\title{
The Acquisition of Epistemic Modality
}

Anna Papafragou ${ }^{1}$ and Ozge Isik Ozturk ${ }^{2}$

${ }^{1}$ Department of Psychology, University of Delaware, USA

${ }^{2}$ Department of Linguistics, University of Delaware, USA

https://doi.org/10.36505/ExLing-2006/01/0044/000044

\begin{abstract}
In this paper we try to contribute to the body of knowledge about the acquisition of English epistemic modal verbs (e.g. Mary may/has to be at school). Semantically, these verbs encode possibility or necessity with respect to available evidence. Prag-matically, the use of epistemic modals often gives rise to scalar conversational infer-ences (Mary may be at school -> Mary doesn't have to be at school). The acquisition of epistemic modals is challenging for children on both these levels. In this paper, we present findings from two studies which were conducted with 5-year-old children and adults. Our findings, unlike previous work, show that 5-yr-olds have mastered epistemic modal semantics, including the notions of necessity and possibility. How-ever, they are still in the process of acquiring epistemic modal pragmatics.
\end{abstract}

\section{Introduction}

This paper is concerned with the acquisition of semantics and pragmatics of epistemic modals. Epistemic modal verbs encode the speaker's certainty towards the probability or predictability status of the proposition embedded under the modal verb. The sentences in (1) are examples of epistemic modality:

(1) a. It has to rain in the afternoon.

b. It may rain afternoon.

On the semantic level epistemic modal operators encode modal force (necessity or possibility) and get interpreted against a conversational background which is a function from possible worlds into sets of propositions. Necessity in a given world encodes truth in all alternative possible worlds, whereas possibility encodes truth in at least one alternative possible world (Hintikka, 1969).

On the pragmatic level, epistemic modal verbs typically give rise to conversational implicatures of the following sort:

(1) a. It has to rain in the afternoon.

b. It may rain in the afternoon.

(2) It does not have to rain in the afternoon.

Logically, (1b) is compatible with (1a). However, in conversation, (1b) excludes (1a) - hence it implicates (2).

ExLing 2006: Proceedings of 1st Tutorial and Research Workshop on Experimental Linguistics, 28-30 August 2006, Athens, Greece 
In order for the child to acquire epistemic modality, he/she needs to acquire both the semantic aspects of modal meaning (including the notions of possibility and necessity) and the pragmatic inferences associated with modal expressions. Our goal in this paper is to shed light on the processes underlying the acquisition of epistemic modality.

\section{Experiment}

\section{Method}

\section{Participants}

A total of 40 native English-speaking-children (mean age: 5;8 mo) and 40 native English-speaking adults participated in this study.

\section{Stimuli and Procedure}

Participants were presented with eight short animated stories on a computer screen. The experimenter told the participant that they would play a game together with two puppets (Minnie and Daisy) which were seated across the computer and several animals which are computer-animated. The test phase of the experiment involved a stage on the screen whose curtains could be lowered and two containers (identical in shape and size but different in color). The experimenter told the participant that each of the animals would hide in one of the boxes on the screen while the stage curtains were lowered, after the curtains were lifted up again, Minnie and Daisy would take turns and guess in which box the animal had hidden. Participants had to say whether they agreed with each puppet or not.

Stories and statements were identical in both conditions except for the modal verb used in the puppets' guesses (may in the Possibility and have to in the Necessity condition). For instance, in one of the stories a mouse hid in one of the two boxes (a yellow or a pink one) while the curtains were lowered. Each story gave the puppets two opportunities to guess. In the first guessing phase (closed boxes phase) the puppets made the following guesses right after the animal was hidden but before any of the boxes were opened:

Possibility Condition

(3) Minnie: "The mouse may be in the yellow box." (True)

(4) Daisy: "The mouse may be in the pink box." (True)

Necessity Condition

(5) Minnie: "The mouse has to be in the yellow box." (False)

(6) Daisy: "The mouse has to be in the pink box." (False) 
After each statement the experimenter asked the participant whether or not the puppet was right. Because of the design of the task, both puppets are correct in the Possibility condition and incorrect in the Necessity condition during this first phase of each story.

In the next guessing phase, one of the boxes was opened. In four of the stories, it revealed that it had the animal inside. For instance, in our earlier story, the yellow box was opened to reveal the animal. The experimenter again asked each of the puppets where the animal was hidden. Depending on the condition the child was assigned to, the puppets offered the answers (36). Again, the experimenter asked the participant whether or not the puppet was right.

In the remaining four stories, there was no animal hidden in the opened box. For instance, a cow hid in one of the two boxes (an orange and a blue one). After the first guessing round, the blue box was opened and was found empty. The puppets offered the answers given below:

Possibility Condition

(7) Minnie: "The cow may be in the orange box." (False)

(8) Daisy: "The cow may be in the blue box." (True but under-informative)

Necessity Condition

(9) Minnie: "The cow has to be in the orange box." (False)

(10) Daisy: "The cow has to be in the blue box." (True but underinformative)

Adults were tested individually in the same way as the children. They were expected to accept the true statements and to reject the false statements in both the Possibility and the Necessity conditions; we also expected them to accept the under-informative statements in both conditions on semantic grounds, even though pragmatic responses were also acceptable. We were interested in examining whether five-year-old children lack the correct semantics and pragmatics for epistemic modals, as previous work has suggested (Noveck, 2001) - hence, whether their responses would be different from adults'.

\section{Results}

Overall, we found that 5 -year-olds have acquired the semantics of the modal of Possibility may and of the modal of Necessity have to, since they successfully accept true modal statements and reject false ones most of the time (for fuller discussion, see Papafragou \& Ozturk, 2006). As expected, we found that adults' performance was better in both the Possibility and Necessity conditions. However, the question of whether 5-year-olds treat a relatively weaker term logically or pragmatically remains open as both the children 
and our adult participants treated these items semantically and not pragmatically (i.e., they did not reject true but underinformative statements).

We have planned future research to examine further questions, specifically, whether children are aware of epistemic modal scales, whether they would be able to treat an informationally weak modal verb pragmatically if it were explicitly contrasted with a stronger modal, and whether they would prefer true modal statements over true but under-informative ones.

\section{Conclusion}

In this paper we investigated 5-year-old children's acquisition of epistemic modality. Interestingly, unlike earlier findings, our data show success on the part of young children with the modal concepts of necessity and possibility. Specifically, we have shown that 5-year-olds have acquired the concepts of possibility and necessity and they are able to reason about statements based on these concepts. These findings may provide an opportunity for linguistic developmental data to throw light on theories of conceptual development and the acquisition of the semantics-pragmatics interface.

\section{References}

Hintikka, J. 1969. Models for Modalities, Reidel, Dordrecht.

Noveck, I. A. 2001. When children are more logical than adults: Experimental investigations of scalar implicature. Cognition, 78(2), 165-188.

Papafragou, A., \& Ozturk, O.I. 2006. On the acquisition of modality. To appear in Penn Working Papers in Linguistics. Dept. of Linguistics, UPenn. 